\title{
Potassium deficiency impact on the photosynthetic apparatus efficiency of radish
}

\author{
M. KUSAKA*,+, H.M. KALAJI* (iD), G. MASTALERCZUK**iD, P. DĄBROWSKI ${ }^{* * *}$ (iD), \\ and K. KOWALCZYK ${ }^{\#}$ (D)
}

Department of Plant Physiology, Institute of Biology, Warsaw University of Life Sciences WULS-SGGW, 159 Nowoursynowska Street, 02-776 Warsaw, Poland

Department of Agronomy, Faculty of Agriculture and Biology, Warsaw University of Life Sciences WULS-SGGW, 159 Nowoursynowska Street, 02-776 Warsaw, Poland**

Department of Environmental Development, Institute of Environmental Engineering, Warsaw University of Life Sciences WULS-SGGW, 159 Nowoursynowska Street, 02-776 Warsaw, Poland ${ }^{* * *}$

Department of Vegetable and Medicinal Plants, Institute of Horticulture Sciences, Warsaw University of Life

Sciences WULS-SGGW, 166 Nowoursynowska Street, 02-787 Warsaw, Poland ${ }^{\#}$

\begin{abstract}
Potassium is an essential nutrient for plants and its limited resources impose the improvement of the fertilizer-use efficiency. To address this issue, it is important to understand its roles in the photosynthesis and to provide a quick, noninvasive method for diagnosing its deficiency in plants. The impact of potassium deficiency on the photochemical phase of photosynthesis has not been well understood. In this work, we present the $\mathrm{K}^{+}$-deficiency effect on gas exchange, chlorophyll content, and electron transport chain in two hybrid cultivars of radish. Our results showed that one of the cultivars proved to be tolerant and maintained the net photosynthetic rate at the level of the control plants. In both cultivars, the effect on the photochemical phase of photosynthesis was observed. We suspect that low $\mathrm{K}^{+}$ availability impaired the balance of the $\mathrm{H}^{+}$influx to thylakoid lumen which increased its acidification and triggered the downregulation mechanism leading to the rearrangement of PSII complexes and an increase in energy dissipation.
\end{abstract}

Keywords: chlorophyll $a$ fluorescence; JIP-test; stomatal conductance; transpiration rate.

\section{Introduction}

Potassium is one of the key nutrients the availability of which strongly determines plant growth and development. The deficiency of this element in arable soils is common.
At the same time, limited resources of potassium fertilizers are now forcing us to improve fertilizer-use efficiency. To address this issue, we need to understand the effect of low $\mathrm{K}^{+}$availability for plants. The possibility of early diagnosis of potassium deficiency in plants would also

\section{Highlights}

- $P_{\mathrm{N}}$ reduction under $\mathrm{K}$ deficiency in radish was not caused by stomatal limitation

- K deficiency affected the thermal phase $(2-30 \mathrm{~ms})$ of chlorophyll $a$ fluorescence transient

- K deficiency affected the PSII connectivity and the redox state of PQ pool
Received 16 July 2020

Accepted 2 November 2020

Published online 15 February 2021

${ }^{+}$Corresponding author

e-mail: magdalena.cetner@gmail.com

Abbreviations: $\mathrm{Chl}$ - chlorophyll; $C_{\mathrm{i}}$ - intercellular $\mathrm{CO}_{2}$ concentration; Cyt $b_{6} f$ - cytochrome $b_{6} f$ complex; DAT - day after treatment; $E$ - transpiration rate; ETC - electron transport chain; $g_{\mathrm{s}}$ - stomatal conductance; $P_{\mathrm{N}}$ - net photosynthetic rate; $\mathrm{PQ} / \mathrm{PQH} \mathrm{H}_{2}-\mathrm{a}$ mobile plastoquinone/plastoquinol; $\mathrm{Q}_{\mathrm{A}}$ - a plastoquinone bounded with PSII subunit D2; $\mathrm{Q}_{\mathrm{B}}$ - a plastoquinone that binds and unbinds from PSII subunit D1; RC - reaction center.

Acknowledgments: This work was supported by Warsaw University of Life Sciences WULS-SGGW (grant number 505-10-010200N00230-99).

Conflict of interest: The authors declare that they have no conflict of interest. 
help improve the fertilizer-use efficiency. Until now, a stress caused by a deficiency of various macronutrients was most often diagnosed based on the visual symptoms, that is when the deficiency of a given nutrient has already caused damage to the plant. Moreover, to obtain reliable information about a plant nutrient status, an analysis of the chemical composition of plant tissue is required. This method is both expensive and time-consuming. Therefore, there is a need for a method that allows for a quick and noninvasive diagnosis of nutrient deficiency in plants, including potassium.

Understanding the exact role of potassium in the plant, including photosynthesis, is the basis for answering these issues. The availability of this component has been positively correlated with photosynthetic productivity of plants. However, the impact of deficiencies of this key nutrient on the course and efficiency of the photochemical phase of photosynthesis has not been well understood.

Potassium, along with nitrogen and phosphorus, is one of the most important nutrients; their availability regulates plant growth and development. However, unlike nitrogen and phosphorus, potassium is not a constituent of organic compounds. In plants, it occurs almost exclusively in ionic form and is one of the most mobile elements. In leaf cells, potassium is mainly found in mitochondria, chloroplasts, and vacuoles (Mengel 2006). Potassium ions activate the action of many enzymes: transferases, oxidoreductases (mainly dehydrogenases), synthetases, kinases, nitrate reductase, enzymes of carbohydrate and protein metabolism, as well as membrane ATPase. The specific functions of potassium ions include regulation of plant water management, transpiration, control of stomata movement, regulation of membrane permeability, and cell osmoregulation. Potassium ions are involved in intercellular and interorgan transport, peptide synthesis, and stress response. The balance between $\mathrm{K}^{+}$and $\mathrm{Na}^{+}$ions regulates the function of chloroplasts, and plants with potassium deficiency show greater sensitivity to light and peroxide overproduction (Pottosin and Shabala 2016). Studies on photosynthetic efficiency in conditions of potassium deficiency have shown a reduction in chlorophyll (Chl) content, net photosynthesis efficiency, and stomatal conductance, inhibition of photosynthetic phosphorylation, reduction of photochemical fluorescence quenching $\left(\mathrm{q}_{\mathrm{P}}\right)$, and electron transport rate through PSII (ETR) as well as a reduction in the activity and concentration of Rubisco in wheat, rice, corn, potato, sweet potato, cotton, and soybean (Osaki et al. 1993, Zhao et al. 2001, Jia et al. 2008, Wang et al. 2015, Liu et al. 2017). Degl'Innocenti et al. (2009) in their research on barley proved that potassium deficiency not only negatively affected $\mathrm{CO}_{2}$ assimilation, but also increased the negative effects of salinity on photosynthesis. At the same time, some researchers reported differences between cultivars of a given species in response to potassium deficiency. Cultivars with high tolerance to this type of stress reduced photosynthetic productivity to a lesser extent (Jia et al. 2008, Zhao et al. 2016, Liu et al. 2017). Liu et al. (2017) in their research on sweet potatoa species with a high demand for potassium - did not report significant changes in the parameters of the JIP-test in a cultivar with an increased tolerance. However, according to Jákli et al. (2017) sunflower potassium deficiency did not directly affect either the PSII quantum yield or Rubisco activity in vivo, and $\mathrm{CO}_{2}$ assimilation was inhibited mainly by reducing stomata conductivity. It has not yet been determined whether sources of limited $\mathrm{CO}_{2}$ assimilation in conditions of potassium deficiency should be sought in photochemical phase disturbances, inhibition of the biochemical phase, or lower $\mathrm{CO}_{2}$ availability resulting from the limitation of gas exchange by stomata.

One of the methods used in the study of the lightdependent phase of photosynthesis is the analysis of direct $\mathrm{Chl} a$ fluorescence. Although fluorescence is a small part of the energy emitted from the photosynthetic apparatus, its analysis allows describing both the functioning and certain structural features of the photosynthetic apparatus (Strasser et al. 2004, Stirbet et al. 2014, Dąbrowski et al. 2016). Detailed fluorescence signal analysis, so-called JIP-test, enables for a noninvasive monitoring of the current functioning of primary photosynthesis reactions in various environmental conditions. The relationship between photosynthesis reactions and Chl fluorescence signals from the JIP-test are based on the theory of energy flow in thylakoid membranes (Strasser et al. 2004). Based on this theory, algebraic equations have been created describing the balance between the inflow and outflow of total energy for analyzed photosynthetic pigment-protein complexes. These equations allow us to obtain information on the probability of the fate of absorbed energy and to characterize energetic communication between PSII components, describing all routes of this communication. Chl $a$ fluorescence measurements and their analysis using the JIP-test are used in studies of plant responses to stress caused by various environmental factors (Strasser et al. 2004, Kalaji et al. 2014, Stirbet et al. 2018, Dąbrowski et al. 2019, Tsimilli-Michael 2020), including nutrient deficiencies (Goltsev et al. 2012, Aleksandrov et al. 2014, Živčák et al. 2014, Cetner et al. 2017, 2020; Horaczek et al. 2020, Samborska-Skutnik et al. 2020).

The study aimed to examine the efficiency of the photochemical phase of photosynthesis, determine the modification of its course and structural changes of pigment-protein complexes in radish (Raphanus sativus var. sativus) growing in conditions of potassium deficiency.

\section{Materials and methods}

Plant material and growth conditions: Two different hybrid cultivars of radish were chosen for the experiments: Raphanus sativus var. sativus 'Suntella F1' (Suntella) and 'Fluo HF1' (Fluo). Plants were grown in a phytotron under controlled conditions. Photoperiod was $14 \mathrm{~h}$, day/night air temperature was $18 / 13^{\circ} \mathrm{C}$, PPFD was $250 \mu$ mol(photon) $\mathrm{m}^{-2} \mathrm{~s}^{-1}$, and $24-\mathrm{h}$ average air humidity was approx. 50\%. Radish was grown in hydroponics, because this method allows for a better control of the amount of nutrients supplied to plants. An innovative material was used as the substrate: polyethylene pellet (PE), which has a low ion absorption capacity as compared to commonly used mineral substrates. The media were developed based on 
Hoagland's medium (Hoagland and Arnon 1950):

\begin{tabular}{lcc}
\hline & Control solution & Experimental solution \\
\hline Macronutrients & {$\left[\mathrm{mmol} \mathrm{L}^{-1}\right]$} & \\
$\mathrm{N}\left(\mathrm{NO}_{3}\right)$ & 11.63 & 12.14 \\
$\mathrm{P}\left(\mathrm{PO}_{4}\right)$ & 1.00 & 1.50 \\
$\mathrm{~K}$ & 6.28 & 0.00 \\
$\mathrm{Ca}$ & 4.00 & 4.00 \\
$\mathrm{Mg}$ & 2.00 & 2.00 \\
$\mathrm{Na}$ & 1.13 & 1.14 \\
$\mathrm{~S}\left(\mathrm{SO}_{4}\right)$ & 3.13 & 0.14 \\
$\mathrm{Cl}$ & 1.00 & 4.00 \\
$\mathrm{Micronutrients}[\mu \mathrm{mol} \mathrm{L}$ & \\
$\mathrm{Fe}$ & 118.48 & 118.48 \\
$\mathrm{~B}$ & 48.57 & 48.57 \\
$\mathrm{Cu}$ & 1.60 & 1.60 \\
$\mathrm{Zn}$ & 0.97 & 0.97 \\
$\mathrm{Mn}$ & 6.51 & 6.51 \\
$\mathrm{Mo}$ & 0.52 & 0.52 \\
\hline
\end{tabular}

Tap water was used for seed germination and initial plant growth (8 d). After that, plants were grown on the control medium for $10 \mathrm{~d}$ until the first pair of true leaves developed. From this moment, the plants were exposed to a stressor; the first day of stress conditions is referred to as 1 DAT. Stress conditions were maintained until over $50 \%$ of plants developed symptoms of potassium deficiency, i.e., chlorotic and necrotic spots, which were observed on 17 DAT. Then the control medium was restored to the plants (regeneration period, $8 \mathrm{~d}$ ).

The fresh and dry mass of leaves as well as the content of selected mineral components were determined 7 times during plants' life cycle: on 1, 3, 6, 10, 15, 20, and 24 DAT. In order to obtain $>1 \mathrm{~g}$ of dry mass for mineral composition analyses, 3 to 27 plants were randomly harvested; after removing roots, bulbs, and cotyledons, leaves were weighed, dried, and then weighed again. The chemical composition analyses were carried out on collective samples of 3-27 randomly selected plants.

Potassium content was determined using atomic emission spectrometry (ICP-AES, Thermo Scientific iCAP 6000, Thermo Fisher Scientific Inc., USA), after mineralization of plant material in $65 \% \mathrm{HNO}_{3}$ and $70 \% \mathrm{HClO}_{4}$ $\left(\mathrm{HNO}_{3}: \mathrm{HClO}_{4}=4: 1\right)$.

In vivo Chl content was determined using Dualex Scientific + TM Polyphenol \& Chlorophyll-Meter (Force-A, France) several times during the vegetation period, at 2-4-d intervals. Measurements were carried out on 2-3 fully developed leaves of nine plants, selected at random and marked before stress conditions were introduced.

Plant gas-exchange parameters: Net photosynthetic rate $\left(P_{\mathrm{N}}\right)$, transpiration rate $(E)$, and stomatal conductance $\left(g_{\mathrm{s}}\right)$ and intercellular concentration of $\mathrm{CO}_{2}\left(C_{\mathrm{i}}\right)$ were determined at approximately 7-d intervals using $L C p r o+$ infrared gas analyzer (ADC BioScientific Ltd., UK). Gas exchange was determined in ambient phytotron conditions: day/night air temperature of $18 / 13^{\circ} \mathrm{C}$, PPFD of $250 \mu \mathrm{mol}$ (photon) $\mathrm{m}^{-2} \mathrm{~s}^{-1}$, and $\mathrm{CO}_{2}$ concentration around $500 \mathrm{ppm}$. Measurements were performed on four fully developed leaves of randomly selected plants.

Chl $\boldsymbol{a}$ fluorescence intensity was measured in vivo using a HandyPEA fluorimeter (Hansatech Instruments Ltd., Norfolk, UK). Measurements were carried out after 30-min adaptation to darkness, on the same leaves of 36 plants selected at random and marked before stress conditions were introduced. Measurement data was used to calculate the JIP-test parameters. The meanings of individual parameters and mathematical formulas used in their calculations are presented in the Appendix.

Statistical analysis: The experimental data were statistically analyzed using one- and two-factor analysis of variance $(A N O V A)$. Significance of treatment effects was analyzed by the Tukey's test at $P$-value $<0.05$. The main components analysis (PCA) was performed to evaluate the relationship between the analyzed features and to characterize multivariate differences between them. Calculations were performed using Microsoft Excel (Microsoft, USA), StatPlus:mac (AnalystSoft Inc., USA), and STATISTICA 13.1 (StatSoft, Tulsa, USA).

\section{Results}

Potassium content in leaves: The optimal potassium content in radish leaves is $>2.0 \%$ (Sanchez et al. 1991). In an experiment on radish growing in potassium deficiency, a reduction of this element to $1.5 \%$ compared to $2.2 \%$ in the control was observed as early as on 1 DAT in case of Suntella(Fig. $1 A$ ), while in Fluo the difference was observed on 3 DAT: 1.9 compared to $2.7 \%$ in the control (Fig. $1 B$ ). The increase in $\mathrm{K}^{+}$concentration in K-deficient Suntella to $1.9 \%$ on 3 DAT may result from the translocation of $\mathrm{K}^{+}$ from cotyledons, which were excluded from the analysis of chemical composition. The low $\mathrm{K}^{+}$content in the leaves of both cultivars was maintained throughout the entire stress period, reaching the lowest level on 15 DAT ( 0.3 and $0.6 \%$ in Suntella and Fluo cultivars, respectively). After restoring the potassium-containing medium (recovery period), the $\mathrm{K}^{+}$content in both cultivars increased to the level observed in the control plants. Radish for a long time did not show symptoms considered typical for potassium deficiency. The wrapping of the edges of the leaf blades and the appearance of necrotic spots between leaf veins on the lower leaves were observed only on 10 DAT. Specific symptoms in approx. 50\% of plants appeared on 14 DAT and were more pronounced in the case of the Suntella cultivar.

Dry mass of leaves: No significant changes in dry mass were observed in potassium-deficient and control plants (Fig. 1C,D). A decrease in dry mass compared to the control sample was observed only on 20 DAT, i.e., during the regeneration period. The reduction in plant mass was 
partly due to the drying and falling off of the old (lower) leaves, especially in the case of the Suntella cultivar.

Chlorophyll content: The Chl content in leaves of plants exposed to potassium deficiency differed between the two cultivars. In the case of the Suntella cultivar, the Chl content remained at or exceeded the control value - a significantly higher value was recorded on 13 DAT (Fig. 2A). However, in the case of Fluo, the Chl content remained at the control level up to 13 DAT, while from 15 DAT it was decreasing; at the end of the growing season, the content of $\mathrm{Chl}$ in the leaves was lower compared to the control (Fig. 2B).
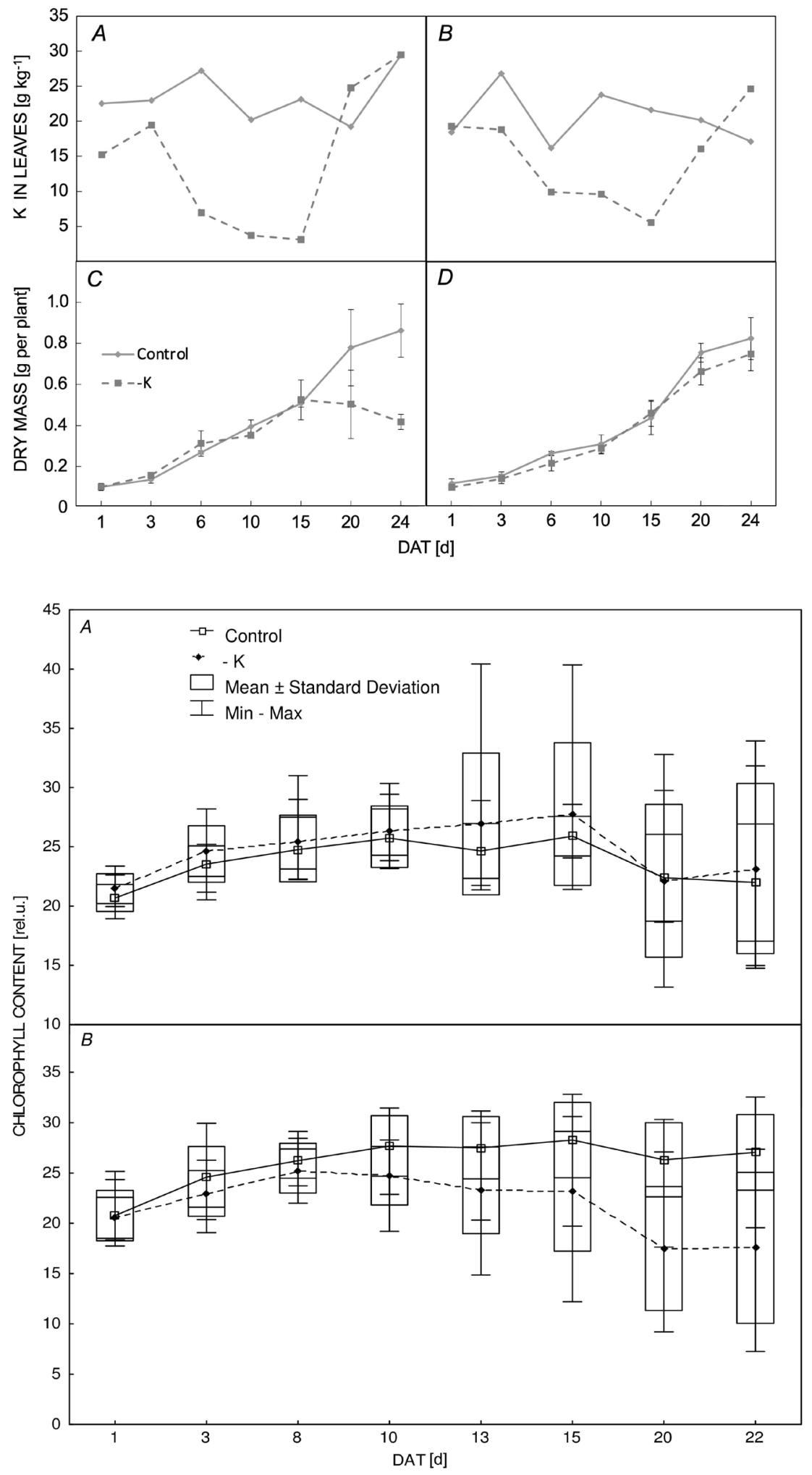

Fig. 1. Impact of potassium deficiency stress on $\mathrm{K}$ content in leaves $(A, B)$ and dry mass per plant $(C, D)$ of two radish cultivars: 'Suntella F1' $(A, C)$ and 'Fluo HF1' $(B, D)$. DAT - days after treatment. K content was evaluated for a pool sample of 3-9 plants. The mean \pm SD for dry mass per plant was calculated from three repetitions.
Fig. 2. Impact of potassium deficiency stress on chlorophyll content of two radish cultivars 'Suntella F1' $(A)$ and 'Fluo HF1' $(B)$. DAT - days after treatment. The mean \pm SD was calculated from nine repetitions. 
Gas-exchange parameters: On the contrary, the net photosynthetic rate $\left(P_{\mathrm{N}}\right)$ decreased only in case of the Suntella cultivar (Fig. $3 A, B$ ), while Fluo was able to maintain $P_{\mathrm{N}}$ at the level of control plants even after $15 \mathrm{DAT}$, when its $\mathrm{Chl}$ content decreased. The transpiration rate $(E)$ in both cultivars remained unchanged as compared to the control sample throughout the growing season (Fig. 3C,D). Moreover, no significant reduction in stomatal conductance $\left(g_{\mathrm{s}}\right)$ was observed (Fig. $\left.3 E, F\right)$. On the contrary, at the beginning of stress, on 3 DAT, more than a two-fold increase in the value of this parameter was noted.

The OJIP curve: Chl $a$ fluorescence analysis showed changes in the shape of the OJIP curve in both cultivars subjected to potassium deficiency stress (Fig. 4). The change in the shape of the curve was more pronounced in young (upper) leaves than that in old (lower) ones (Fig. $4 C, D$ ). This may indicate that light phase disorders affected young leaves to a greater extent, despite the high $\mathrm{K}^{+}$mobility and the ease of their translocation to developing tissues. Additionally, the rise in fluorescence intensity was higher in the case of Suntella, which also showed a decrease in $P_{\mathrm{N}}$. Increased fluorescence intensity was observed mainly in the $\mathrm{J}-\mathrm{I}$ phase $(2-30 \mathrm{~ms})$, i.e., at the beginning of the so-called thermal phase. The phase was named so because of its sensitivity to temperature, which results from the initiation of the electron exchange between $\mathrm{PQH}_{2} / \mathrm{PQ}$ and $\mathrm{Q}_{\mathrm{B}}$ and then cytochrome (Cyt) $b_{6} f$
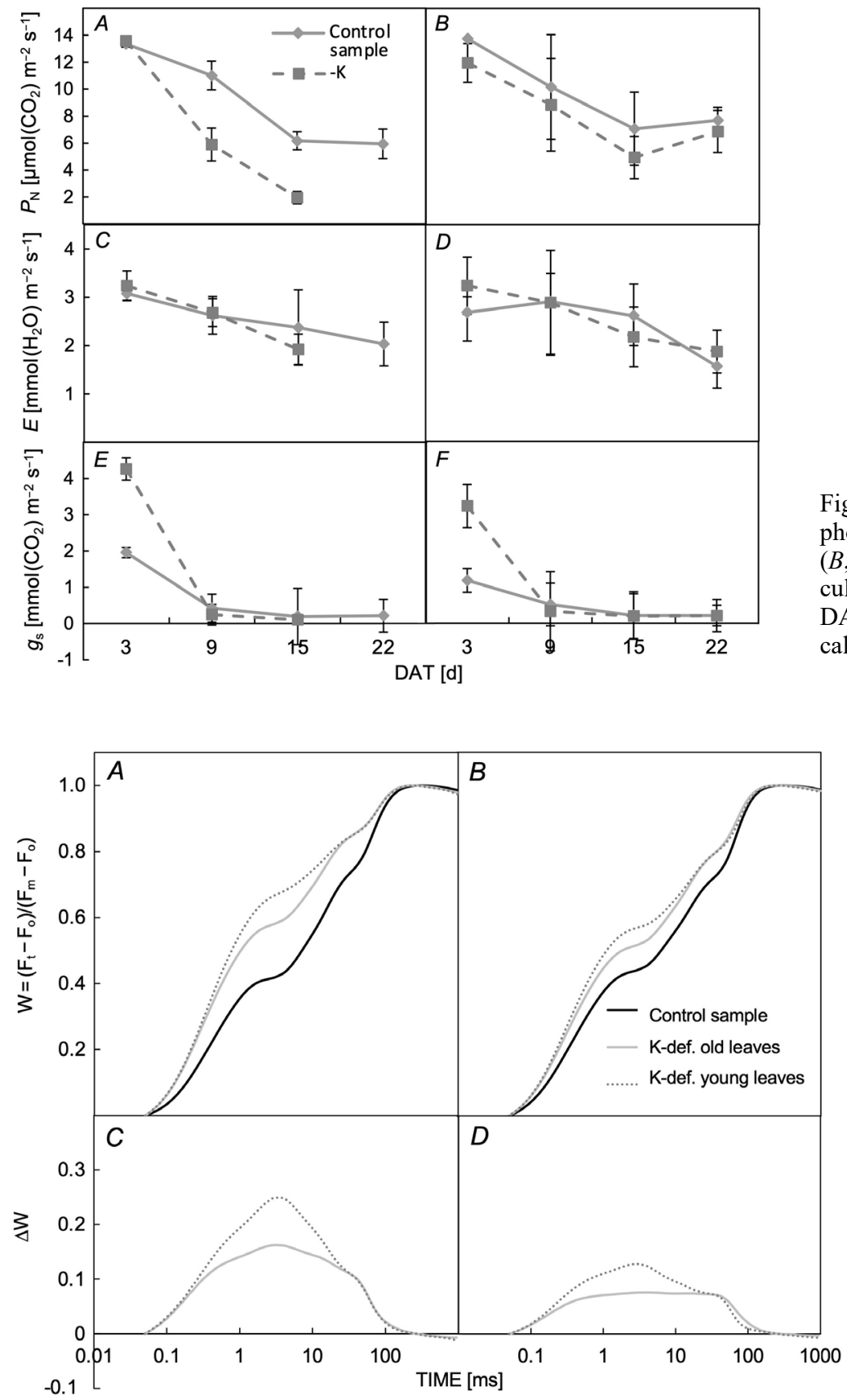

Fig. 3. Impact of potassium deficiency stress on net photosynthesis rate, $P_{\mathrm{N}}(A, B)$, transpiration rate, $E$ $(B, C)$, and stomatal conductance, $g_{\mathrm{s}}(E, F)$ of two radish cultivars: 'Suntella F1' $(A, C, E)$ and 'Fluo HF1' $(B, D, F)$. DAT - days after treatment. The mean \pm SD was calculated from three repetitions.
Fig. 4. Changes in the shape of relative chlorophyll $a$ fluorescence fast induction curves revealed from dark-adapted leaves of different age (old, bottom leaves, and young, upper leaves) of K-deficient Raphanus sativus var. sativus cultivars 'Suntella F1' $(A, C)$ and 'Fluo HF1' $(B, D)$ on 15 DAT. The curves were double normalized $\left[\mathrm{W}=\left(\mathrm{F}_{\mathrm{t}}-\mathrm{F}_{\mathrm{o}}\right) /\left(\mathrm{F}_{\mathrm{m}}-\mathrm{F}_{\mathrm{o}}\right)\right.$, where $\mathrm{F}_{\mathrm{o}}=\mathrm{F}_{0.05 \mathrm{~ms}}, \mathrm{~F}_{\mathrm{m}}=$ maximal fluorescence value, and $\mathrm{F}_{\mathrm{t}}=$ fluorescence value at given time $\mathrm{t}$; panels $A, B]$ and presented as difference transients $\Delta \mathrm{W}$ between stressed and control samples (panels $C, D$ ). Mean values were derived from 36 measurements per treatment. 
(Stirbet and Govindjee 2012). While the course of the photochemical phase $(\mathrm{O}-\mathrm{J})$ is affected mainly by PSII activity, the thermal phase is additionally affected by PSI activity. According to Stirbet and Govindjee (2012), in the J-I-P phase, the PSII reaction centers are still gradually closing, with the parallel reduction of the plastoquinone pool.

The JIP-test: The results of the JIP-test are presented in Table 1. A decrease in the quantum yield of primary PSII photochemistry $\left(\phi_{\mathrm{Po}}\right)$ revealed disorders in PSII.
We also observed changes in parameters connected with the mechanisms protecting PSII against photoinhibition, i.e., disconnection of LHCII complexes (increase in $\mathrm{F}_{0}$; with the exception of old leaves of K-deficient Suntella plants), reduction in the number of active reaction centers $(\mathrm{RC} / \mathrm{ABS})$ and the number of $\mathrm{Q}_{\mathrm{A}}$ reduction events $(\mathrm{N})$ followed by an increase in the net rate of the RCs' closure $\left(\mathrm{M}_{0}\right)$. The density of active RC PSII per cross-section $\left(\mathrm{RC} / \mathrm{CS}_{0}\right)$ remained at the level of the control sample in Fluo, but it decreased in the case of Suntella. This is probably due to Suntella's high Chl content, and thus a

Table 1. Impact of potassium deficiency on the values of the JIP-test parameters of two radish cultivars 'Suntella F1' and 'Fluo HF1' on 15 DAT. The mean \pm SE was calculated from 20-36 observations. Data were analyzed using two-factor ANOVA. Significant differences were marked $*(\alpha=0.05)$, ns - no difference.

\begin{tabular}{|c|c|c|c|c|}
\hline \multirow[t]{2}{*}{ Parameter } & \multicolumn{2}{|l|}{ Old leaves } & \multicolumn{2}{|l|}{ Young leaves } \\
\hline & Control sample & $-\mathrm{K}$ & Control sample & $-\mathrm{K}$ \\
\hline \multicolumn{5}{|c|}{ 'Suntella F1' } \\
\hline $\mathrm{F}_{\mathrm{o}}=\mathrm{F}_{0.05 \mathrm{~ms}}$ & $678 \pm 55$ & $832 \pm 67^{\mathrm{ns}}$ & $638 \pm 19$ & $909 \pm 48^{*}$ \\
\hline $\mathrm{F}_{\mathrm{m}}$ & $3,222 \pm 41$ & $2,488 \pm 162^{*}$ & $3,304 \pm 40$ & $2,222 \pm 137^{*}$ \\
\hline $\mathrm{T}_{\mathrm{Fm}}$ & $304.444 \pm 9.228$ & $275.000 \pm 29.437^{\mathrm{ns}}$ & $335.278 \pm 12.094$ & $302.000 \pm 36.256^{\mathrm{ns}}$ \\
\hline $\mathrm{M}_{0}$ & $0.703 \pm 0.036$ & $1.194 \pm 0.079^{*}$ & $0.575 \pm 0.018$ & $1.198 \pm 0.078^{*}$ \\
\hline $\mathrm{N}$ & $20.103 \pm 0.946$ & $17.040 \pm 0.982^{*}$ & $21.791 \pm 0.344$ & $16.757 \pm 0.506^{*}$ \\
\hline$\phi_{\mathrm{Po}}$ & $0.793 \pm 0.013$ & $0.627 \pm 0.038^{*}$ & $0.807 \pm 0.005$ & $0.561 \pm 0.032^{*}$ \\
\hline$\phi_{\text {Eo }}$ & $0.470 \pm 0.012$ & $0.261 \pm 0.032^{*}$ & $0.508 \pm 0.007$ & $0.198 \pm 0.026^{*}$ \\
\hline$\phi_{\mathrm{Ro}}$ & $0.187 \pm 0.006$ & $0.099 \pm 0.010^{*}$ & $0.256 \pm 0.004$ & $0.088 \pm 0.009^{*}$ \\
\hline$\psi_{\mathrm{Eo}}$ & $0.589 \pm 0.008$ & $0.382 \pm 0.032^{*}$ & $0.629 \pm 0.006$ & $0.331 \pm 0.028^{*}$ \\
\hline$\delta_{\text {Ro }}$ & $0.405 \pm 0.014$ & $0.443 \pm 0.038^{\mathrm{ns}}$ & $0.505 \pm 0.006$ & $0.484 \pm 0.028^{\mathrm{ns}}$ \\
\hline $\mathrm{RC} / \mathrm{ABS}$ & $0.484 \pm 0.015$ & $0.335 \pm 0.023^{*}$ & $0.530 \pm 0.010$ & $0.327 \pm 0.023^{*}$ \\
\hline $\mathrm{TR}_{0} / \mathrm{RC}$ & $1.686 \pm 0.045$ & $1.907 \pm 0.036^{*}$ & $1.540 \pm 0.026$ & $1.763 \pm 0.050^{*}$ \\
\hline $\mathrm{ET}_{0} / \mathrm{RC}$ & $0.983 \pm 0.014$ & $0.713 \pm 0.053^{*}$ & $0.965 \pm 0.014$ & $0.565 \pm 0.039^{*}$ \\
\hline $\mathrm{RE}_{0} / \mathrm{RC}$ & $0.398 \pm 0.017$ & $0.285 \pm 0.014^{*}$ & $0.488 \pm 0.010$ & $0.259 \pm 0.011^{*}$ \\
\hline $\mathrm{PI}_{\mathrm{abs}}$ & $3.138 \pm 0.180$ & $0.874 \pm 0.214^{*}$ & $3.985 \pm 0.177$ & $0.455 \pm 0.137^{*}$ \\
\hline $\mathrm{PI}_{\mathrm{tot}}$ & $2.138 \pm 0.172$ & $0.677 \pm 0.204^{*}$ & $4.077 \pm 0.200$ & $0.343 \pm 0.087^{*}$ \\
\hline $\mathrm{RC} / \mathrm{CS}_{0}$ & $303.276 \pm 4.141$ & $262.038 \pm 15.604^{*}$ & $332.06 \pm 2.908$ & $284.834 \pm 16.568^{*}$ \\
\hline \multicolumn{5}{|l|}{ 'Fluo HF1' } \\
\hline $\mathrm{F}_{\mathrm{o}}=\mathrm{F}_{0.05 \mathrm{~ms}}$ & $671 \pm 42$ & $810 \pm 42^{*}$ & $679 \pm 22$ & $884 \pm 37^{*}$ \\
\hline $\mathrm{F}_{\mathrm{m}}$ & $3,137 \pm 42$ & $2,796 \pm 101^{*}$ & $3,234 \pm 39$ & $2,745 \pm 85^{*}$ \\
\hline $\mathrm{T}_{\mathrm{Fm}}$ & $300.294 \pm 8.647$ & $237.500 \pm 6.671^{*}$ & $305.833 \pm 9.406$ & $241.250 \pm 9.287^{*}$ \\
\hline $\mathrm{M}_{0}$ & $0.706 \pm 0.044$ & $1.023 \pm 0.048^{*}$ & $0.677 \pm 0.026$ & $1.099 \pm 0.061^{*}$ \\
\hline $\mathrm{N}$ & $21.299 \pm 0.731$ & $17.705 \pm 0.567^{*}$ & $21.160 \pm 0.365$ & $18.819 \pm 0.479^{*}$ \\
\hline$\phi_{\text {Рo }}$ & $0.785 \pm 0.014$ & $0.699 \pm 0.017^{*}$ & $0.791 \pm 0.005$ & $0.666 \pm 0.018^{*}$ \\
\hline$\phi_{\mathrm{Eo}}$ & $0.466 \pm 0.015$ & $0.337 \pm 0.019^{*}$ & $0.465 \pm 0.010$ & $0.289 \pm 0.021^{*}$ \\
\hline$\phi_{\text {Ro }}$ & $0.228 \pm 0.006$ & $0.148 \pm 0.008^{*}$ & $0.242 \pm 0.007$ & $0.141 \pm 0.009^{*}$ \\
\hline$\psi_{\mathrm{Eo}}$ & $0.587 \pm 0.012$ & $0.471 \pm 0.018^{*}$ & $0.587 \pm 0.009$ & $0.421 \pm 0.022^{*}$ \\
\hline$\delta_{\mathrm{Ro}}$ & $0.502 \pm 0.016$ & $0.447 \pm 0.014^{*}$ & $0.518 \pm 0.008$ & $0.509 \pm 0.015^{\mathrm{ns}}$ \\
\hline $\mathrm{RC} / \mathrm{ABS}$ & $0.483 \pm 0.016$ & $0.378 \pm 0.016^{*}$ & $0.493 \pm 0.011$ & $0.371 \pm 0.018^{*}$ \\
\hline $\mathrm{TR}_{0} / \mathrm{RC}$ & $1.672 \pm 0.044$ & $1.917 \pm 0.052^{*}$ & $1.623 \pm 0.027$ & $1.868 \pm 0.054^{*}$ \\
\hline $\mathrm{ET}_{0} / \mathrm{RC}$ & $0.967 \pm 0.014$ & $0.894 \pm 0.035^{\text {ns }}$ & $0.945 \pm 0.013$ & $0.769 \pm 0.035^{*}$ \\
\hline $\mathrm{RE}_{0} / \mathrm{RC}$ & $0.483 \pm 0.014$ & $0.403 \pm 0.024^{*}$ & $0.490 \pm 0.010$ & $0.381 \pm 0.015^{*}$ \\
\hline $\mathrm{PI}_{\mathrm{abs}}$ & $3.199 \pm 0.238$ & $1.300 \pm 0.202^{*}$ & $2.984 \pm 0.218$ & $1.006 \pm 0.213^{*}$ \\
\hline $\mathrm{PI}_{\mathrm{tot}}$ & $3.004 \pm 0.214$ & $0.988 \pm 0.146^{*}$ & $3.330 \pm 0.269$ & $0.927 \pm 0.192^{*}$ \\
\hline $\mathrm{RC} / \mathrm{CS}_{0}$ & $303.451 \pm 4.321$ & $290.133 \pm 8.979^{\mathrm{ns}}$ & $327.830 \pm 3.913$ & $311.868 \pm 9.191^{\mathrm{ns}}$ \\
\hline
\end{tabular}


necessity of protection of the photosynthetic apparatus against photoinhibition by converting a greater amount of $\mathrm{RC}$ into so-called silent $\mathrm{RCs}$, non- $\mathrm{Q}_{\mathrm{A}}^{-}$-reducing $\mathrm{RCs}$ which dissipate the excessive energy (Strasser et al. 2004). Parameters which characterize quantum yields of electron transport $\left(\phi_{\mathrm{E}}\right)$, electron transport until PSI electron acceptors $\left(\phi_{\mathrm{R}_{0}}\right)$, as well as efficiency/probability with which an electron trapped in PSII RC is transferred beyond $\mathrm{Q}_{\mathrm{A}}^{-}\left(\psi_{\mathrm{Eo}}\right)$ were reduced to a greater extent, although the parameter $\delta_{\text {Ro }}$, which describes efficiency/probability with which an electron from $\mathrm{Q}_{\mathrm{B}}$ is transferred until PSI acceptors, decreased only in the case of old leaves of the the Fluo cultivar. Although trapped energy flux per RC $\left(\mathrm{TR}_{0} / \mathrm{RC}\right)$ increased as compared to the control sample, the electron transport flux further than $\mathrm{Q}_{\mathrm{A}^{-}}\left(\mathrm{ET}_{0} / \mathrm{RC}\right)$ and electron transport flux until PSI acceptors $\left(\mathrm{RE}_{0} / \mathrm{RC}\right)$ were significantly lower. As a result, the performance indexes for energy conservation from photons absorbed by PSII antenna to the reduction of $\mathrm{Q}_{\mathrm{B}}\left(\mathrm{PI}_{\mathrm{abs}}\right)$ and PSI acceptors $\left(\mathrm{PI}_{\mathrm{tot}}\right)$ decreased.

The principal component analysis: The results of PCA analysis were shown in Fig. 5. The first component (PC1) explains $78.1 \%$ of the tested variation, the second (PC2) $14.0 \%$. Potassium availability strongly affected the plant mass (FW, DM), values of the JIP-test parameters $\left(\mathrm{RC} / \mathrm{ABS}, \mathrm{ET}_{0} / \mathrm{RC}, \mathrm{PI}_{\mathrm{tot}}, \mathrm{PI}_{\mathrm{abs}}, \mathrm{F}_{\mathrm{v}} / \mathrm{F}_{\mathrm{m}}\right.$ ) as well as the intensity of photosynthesis $\left(P_{\mathrm{N}}\right)$, transpiration $(E)$, and potassium content in plants $(\mathrm{K})$. These features were significantly positively correlated. Simultaneously, trapped energy flux per $\mathrm{RC}\left(\mathrm{TR}_{0} / \mathrm{RC}\right)$ was negatively correlated, whereas the Chl content in plants was not correlated with these characteristics.

\section{Discussion}

Two radish cultivars showed different reaction to potassium deficiency. The overall stress reaction was more pronounced in the case of the Suntella cultivar; its $\mathrm{K}^{+}$content decreased earlier and to a greater extent, plants developed more severe deficiency symptoms, net photosynthetic rate decreased, and more absorbed energy was reemitted as $\mathrm{Chl} a$ fluorescence. The only feature that remained unaffected in Suntella was its Chl content. At the same time, the Chl content in Fluo decreased significantly after 15 DAT which is around the time the deficiency symptoms were fully developed. A slight decrease in the $\mathrm{Chl}$ content at the end of the vegetation period in the case of Suntella was most likely due to the leaf senescence.

A similar observation, i.e., significantly different $\mathrm{Chl}$ content in two maize cultivars under potassium deficiency was found by Zhao et al. (2016). In studies of Zhao et al. (2016), one of the cultivars showed a higher tolerance to potassium deficiency stress, which was manifested in the ability to maintain a high $\mathrm{Chl}$ content as well as higher $P_{\mathrm{N}}$ and yield of PSII primary photochemical reactions as compared to the sensitive cultivar. However, in our experiment with radish growing in conditions of potassium deficiency, the opposite results were observed. The cultivar which showed no decrease in $\mathrm{Chl}$ content proved to be the sensitive one and $\mathrm{Chl}$ content did not show a correlation with photosynthetic productivity (Fig. 5). These findings combined with the JIP-test results allow for a conclusion, that in the case of the Suntella cultivar a substantial amount of energy absorbed in light-harvesting complexes was dissipated due to employment of photoprotective mechanisms, including structural rearrangements of the

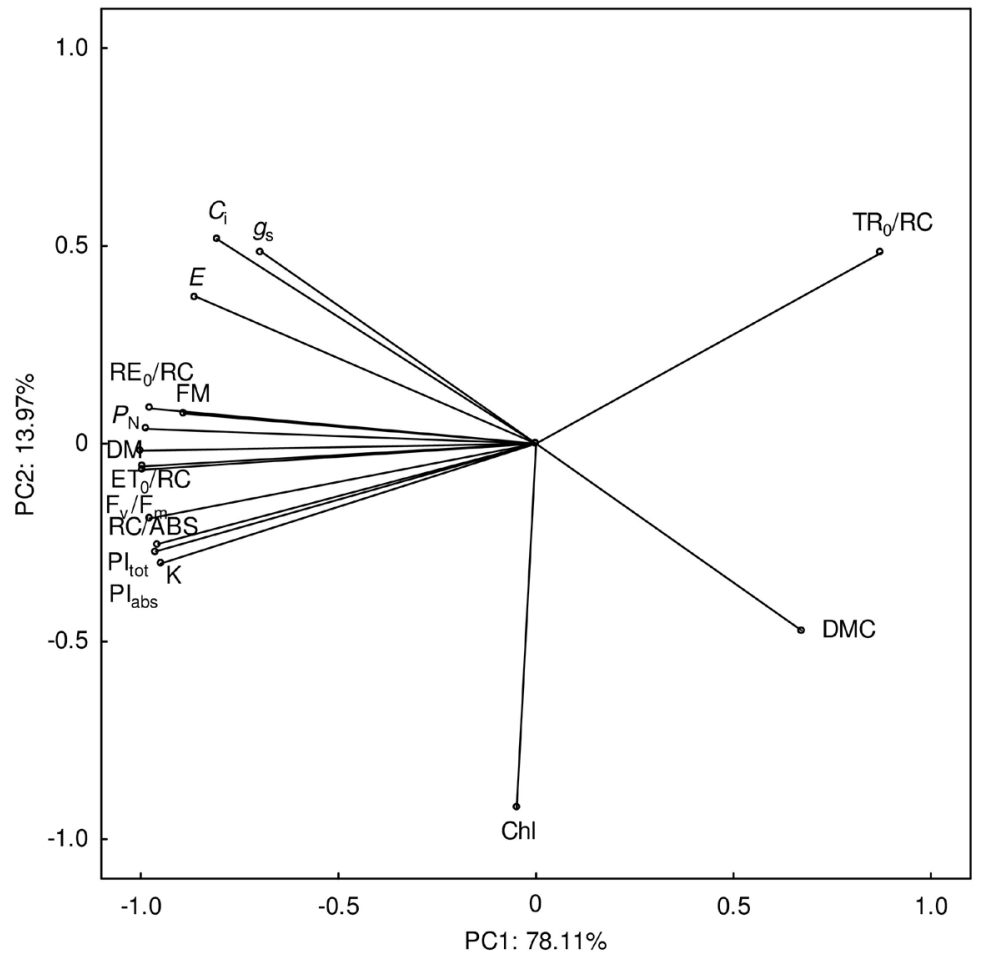

Fig. 5. Principal component analysis (PCA) of K-deficiency stress effect on photosynthetic activity in leaves of radish plants during vegetation period. PCA is based on combined data from fresh mass (FM), dry mass (DM), dry mass content (DMC), net photosynthetic rate $\left(P_{\mathrm{N}}\right)$, transpiration rate $(E)$, stomatal conductance $\left(g_{\mathrm{s}}\right)$, intercellular $\mathrm{CO}_{2}$ concentration $\left(C_{\mathrm{i}}\right)$, chlorophyll content $(\mathrm{Chl})$, and the JIP-test parameters (as described in Appendix) measured in leaves of radish cultivars 'Fluo HF1' and 'Suntella F1'. The arrows present vectors in PC coordinates, reflecting the influence of corresponding parameter on the calculated values of PC1 and PC2. 
complexes (LHCII detachment) and increased number of silent RCs.

In their research on cotton and sunflower growing in potassium-deficient conditions, Bednarz et al. (1998) and Jákli et al. (2017) concluded that the main reason for the reduction of $P_{\mathrm{N}}$ of plants was stomatal limitation. On the contrary, Arquero et al. (2006) observed enhanced stomatal conductance in both well-irrigated and water-stressed olive trees and concluded that moderate $\mathrm{K}$ deficiency may impair the plant's ability to regulate stomatal closure. Stomatal closure impairment caused by a moderate $\mathrm{K}$-deficiency stress could be the reason for the increase in stomatal conductance observed on 3 DAT in radish. K deficiency is also associated with decreased transpiration rates (Arquero et al. 2006). Although a crucial role of $\mathrm{K}^{+}$ in cell osmoregulation, turgor maintenance, and stomatal function has been established, the complexity of stomata behavior under real-world conditions (Shabala 2003) makes difficult to draw clear conclusions on the relationship between potassium nutrition and plant water status and/or stomatal activity. Nevertheless, in the experiment on radish under K-deficiency conditions, neither transpiration rate nor stomatal conductance decreased. Moreover, we conclude that stomatal conductance was not among the factors limiting $\mathrm{CO}_{2}$ assimilation in the case of the Suntella cultivar. Hence, we speculate that the mechanisms underlying the limitation of $\mathrm{CO}_{2}$ accumulation may result from a decrease in Rubisco activity and/or disorders in photochemical phase of photosynthesis.

The analysis of Chl $a$ fluorescence pointed out the beginning of the so-called thermal phase, from 2 to $30 \mathrm{~ms}$, as a place where major disturbances occurred. Reported factors that affect the course of the thermal phase include the redox state of the plastoquinone pool, PSII connectivity, PSII and plastoquinone pool size heterogenity, as well as alternative electron transport pathways (Stirbet and Govindjee 2012). Our results suggest that K deficiency affected the PSII connectivity and the redox state of PQ pool in radish. Therefore, factors that influence $\mathrm{PQ} / \mathrm{PQH}_{2}$ exchange reactions, i.e., $\mathrm{pH}$ at the reaction site, proton gradient, and electric potential across the thylakoid membrane, require special attention in this kind of stress. The transmembrane $\mathrm{pH}$ gradient is generated by the activity of plastoquinones at PSII acceptor side; on the other hand, the $\mathrm{pH}$ gradient plays additional role in the feedback downregulation of light harvesting and electron transport (Galvis et al. 2020). There are certain thresholds of proton concentration, above which the two processes of feedback downregulation are induced; below lumen $\mathrm{pH}$ of 6.8 , the protonation of the thylakoid PsbS protein occurs, which leads to the rearrangement of PSII complexes and an increase in the thermal dissipation of absorbed energy, while below lumen $\mathrm{pH}$ of $6.5, \mathrm{PQH}_{2}$ oxidation at the Cyt $b_{6} f$ complex is restrained (Galvis et al. 2020). In their research on phosphorus-deficient barley, Carstensen et al. (2018) reported that the mechanism of preventing $\mathrm{PQH}_{2}$ oxidation by lumen acidification affected the Chl $a$ fluorescence induction curve by flattening the I-step. The I-step, i.e., the point of inflection of the curve at $30 \mathrm{~ms}$, results from balancing the reduction of the plastoquinones on the acceptor side of PSII and their oxidation at the
Cyt $b_{6} f$ complex; at this stage, $\mathrm{PQH}_{2}$ oxidation reaches its maximum rate because the subsequent ETC carriers after Cyt $b_{6} f$ remain oxidized (Schansker et al. 2005, Stirbet and Govindjee 2012). Radish growing under potassium deficiency showed a clear I-step, which indicate that $\mathrm{PQH}_{2}$ oxidation might be slowed down, yet not entirely blocked. This may result from $\mathrm{K}^{+}$and $\mathrm{Mg}^{2+}$ role in balancing the $\mathrm{H}^{+}$ efflux to thylakoid lumen. It was suggested that $\mathrm{Cl}^{-}$efflux from and $\mathrm{Mg}^{2+}$ and $\mathrm{K}^{+}$influx to the stroma are the major counterion fluxes balancing the light-driven $\mathrm{H}^{+}$efflux to thylakoid lumen (Pottosin and Shabala 2016, Lyu and Lazár 2017). At physiological ionic conditions (at the concentration of $\mathrm{K}^{+}>5 \mathrm{mM}$ ), $\mathrm{K}^{+}$influx appears to be more important for the charge balance, while $\mathrm{Mg}^{2+}$ efflux most likely plays a regulatory role, connecting stromal metabolism to light reactions. At low $\mathrm{K}^{+}$concentration ( $<5 \mathrm{mM}), \mathrm{Mg}^{2+}$ flux will dominate the charge balance (Hind et al. 1974, Pottosin and Shabala 2016). The ability to balance lumen $\mathrm{pH}$ in low $\mathrm{K}^{+}$availability could have been the reason for the employment of the downregulation feedback which leads to the rearrangement of PSII complexes and an increase in the thermal dissipation of absorbed energy rather than limiting $\mathrm{PQH}_{2}$ oxidation at the Cyt $b_{6} f$ complex in K-deficient radish.

Overall, our results showed that two hybrid cultivars of radish reacted to potassium deficiency in a different manner. The Fluo cultivar showed a greater tolerance to this type of stress as compared to the Suntella cultivar, by maintaining the $\mathrm{CO}_{2}$ assimilation at the level of the control sample throughout the stress period. Our results did not support a negative effect of $\mathrm{K}$ deficiency on the transpiration rate and did not show stomatal limitation as the main reason for the reduction of net photosynthetic rate in this type of stress in radish. We conclude that a moderate K-deficiency stress impairs the plant's ability to regulate stomatal closure. Ideally, these findings should be replicated in a study where plants are subjected to various levels of potassium deficiency.

Results of our research demonstrate the effect of potassium deficiency on the photochemical phase of photosynthesis in both tolerant and sensitive cultivars of radish. The analyses lead to the suspicion that low $\mathrm{K}^{+}$availability impaired the balance of the $\mathrm{H}^{+}$influx to thylakoid lumen and increased its acidification, which triggered the downregulation mechanism leading to the rearrangement of PSII complexes by LHCII detachment and an increase in energy dissipation, yet without preventing the $\mathrm{PQH}_{2}$ oxidation at the Cyt $b_{6} f$ complex. However, the mechanisms of $\mathrm{K}^{+}$deficiency underlying processes reflected in $\mathrm{Chl}$ fluorescence induction curve and the JIP-test analysis remain speculative. Future investigations are necessary to validate the conclusions that can be drawn from this study. Despite the limitations of these findings, they add to a growing corpus of research showing the impact of nutrient deficiency stress on the efficiency and structure of the photosynthetic apparatus.

\section{References}

Aleksandrov V., Krasteva V., Paunov M. et al.: Deficiency of some nutrient elements in bean and maize plants analyzed by luminescent method. - Bulg. J. Agric. Sci. 20: 24-30, 2014. 
Arquero O., Barranco D., Benlloch M.: Potassium starvation increases stomatal conductance in olive trees. - HortScience 41: 433-436, 2006.

Bednarz C.W., Oosterhuis D.M., Evans R.D.: Leaf photosynthesis and carbon isotope discrimination of cotton in response to potassium deficiency. - Environ. Exp. Bot. 39: 131-139, 1998.

Carstensen A., Herdean A., Schmidt S.B. et al.: The Impacts of phosphorus deficiency on the photosynthetic electron transport chain. - Plant Physiol. 177: 271-284, 2018.

Cetner M.D., Kalaji H.M., Borucki W., Kowalczyk K.: Phosphorus deficiency affects the I-step of chlorophyll $a$ fluorescence induction curve of radish. - Photosynthetica 58: 671-681, 2020.

Cetner M.D., Kalaji H.M., Goltsev V. et al.: Effects of nitrogen deficiency on efficiency of light-harvesting apparatus in radish. - Plant Physiol. Bioch. 119: 81-92, 2017.

Dąbrowski P., Baczewska A.H., Pawluśkiewicz B. et al.: Prompt chlorophyll a fluorescence as a rapid tool for diagnostic changes in PSII structure inhibited by salt stress in Perennial ryegrass. - J. Photoch. Photobio. B 157: 22-31, 2016.

Dąbrowski P., Baczewska-Dąbrowska A.H., Kalaji H.M. et al.: Exploration of chlorophyll $a$ fluorescence and plant gas exchange parameters as indicators of drought tolerance in perennial ryegrass. - Sensors-Basel 19: 2736, 2019.

Degl'Innocenti E., Hafsi C., Guidi L., Navari-Izzo F.: The effect of salinity on photosynthetic activity in potassium-deficient barley species. - J. Plant Physiol. 166: 1968-1981, 2009.

Galvis V.C., Strand D.D., Messer M. et al.: $\mathrm{H}^{+}$transport by $\mathrm{K}^{+}$ EXCHANGE ANTIPORTER3 promotes photosynthesis and growth in chloroplast ATP synthase mutants. - Plant Physiol. 182: 2126-2142, 2020.

Goltsev V., Zaharieva I., Chernev P. et al:: Drought-induced modifications of photosynthetic electron transport in intact leaves: Analysis and use of neural networks as a tool for a rapid non-invasive estimation. - BBA-Bioenergetics 1817: 1490-1498, 2012.

Hind G., Nakatani H.Y., Izawa S.: Light-dependent redistribution of ions in suspensions of chloroplast thylakoid membranes. P. Natl. Acad. Sci. USA 71: 1484-1488, 1974.

Hoagland D.R., Arnon D.I.: The water-culture method for growing plants without soil. Pp. 32. The College of Agriculture, University of California, Berkeley 1950.

Horaczek T., Dąbrowski P., Kalaji H.M. et al.: JIP-test as a tool for early detection of the macronutrients deficiency in Miscanthus plants. - Photosynthetica 58: 507-517, 2020.

Jákli B., Tavakol E., Tränkner M. et al.: Quantitative limitations to photosynthesis in K deficient sunflower and their implications on water-use efficiency. - J. Plant Physiol. 209: 20-30, 2017.

Jia Y., Yang X., Islam E., Feng Y.: Effects of potassium deficiency on chloroplast ultrastructure and chlorophyll fluorescence in inefficient and efficient genotypes of rice. - J. Plant Nutr. 31: 2105-2118, 2008.

Kalaji H.M., Oukarroum A., Alexandrov V. et al.: Identification of nutrient deficiency in maize and tomato plants by in vivo chlorophyll $a$ fluorescence measurements. - Plant Physiol. Bioch. 81: 16-25, 2014.

Liu M., Zhang A., Chen X. et al.: The effect of potassium deficiency on growth and physiology in sweetpotato [Ipomoea batatas (L.) Lam.] during early growth. - HortScience 52: 1020-1028, 2017.

Lyu H., Lazár D.: Modeling the light-induced electric potential difference $\Delta \Psi$ across the thylakoid membrane based on the transition state rate theory. - BBA-Bioenergetics 1858: 239-248, 2017.

Mengel K.: Potassium. - In: Barker A.V., Pilbeam D.J. (ed.): Handbook of Plant Nutrition. Books in Soils, Plants, and the
Environment (Book 117). CRC Press, 2006. ISBN: 978-08247-5904-9.

Osaki M., Shinano T., Tadano T.: Effect of nitrogen, phosphorus, or potassium deficiency on the accumulation of ribulose1,5-bisphosphate carboxylase/oxygenase and chlorophyll in several field crops. - Soil Sci. Plant Nut. 39: 417-425, 1993.

Pottosin I., Shabala S.: Transport across chloroplast membranes: Optimizing photosynthesis for adverse environmental conditions. - Mol. Plant 9: 356-370, 2016.

Samborska-Skutnik I.A., Kalaji H.M., Sieczko L., Bąba W.: Structural and functional response of photosynthetic apparatus of radish plants to iron deficiency. - Photosynthetica 58: 205-213, 2020.

Sanchez C.A., Lockhart M., Porter P.S.: Response of radish to phosphorus and potassium fertilization on Histosols. HortScience 26: 30-32, 1991.

Schansker G., Tóth S.Z., Strasser R.J.: Methylviologen and dibromothymoquinone treatments of pea leaves reveal the role of photosystem I in the $\mathrm{Chl} a$ fluorescence rise OJIP. BBA-Bioenergetics 1706: 250-261, 2005.

Shabala S.: Regulation of potassium transport in leaves: from molecular to tissue level. - Ann. Bot.-London 92: 627-634, 2003.

Stirbet A., Govindjee: On the relation between the Kautsky effect (chlorophyll $a$ fluorescence induction) and Photosystem II: basics and applications of the OJIP fluorescence transient. J. Photoch. Photobio. B 104: 236-257, 2011.

Stirbet A., Govindjee: Chlorophyll $a$ fluorescence induction: a personal perspective of the thermal phase, the J-I-P rise. Photosynth. Res. 113: 15-61, 2012.

Stirbet A., Lazár D., Kromdijk J., Govindjee: Chlorophyll $a$ fluorescence induction: Can just a one-second measurement be used to quantify abiotic stress responses? - Photosynthetica 56: 86-104, 2018.

Stirbet A., Riznichenko G.Yu., Rubin A.B., Govindjee: Modeling chlorophyll $a$ fluorescence transient: Relation to photosynthesis. - Biochemistry-Moscow+ 79: 291-323, 2014.

Strasser R.J., Tsimilli-Michael M., Srivastava A.: Analysis of the chlorophyll $a$ fluorescence transient. - In: Papageorgiou G.C., Govindjee (ed.): Chlorophyll $a$ Fluorescence: A Signature of Photosynthesis. Advances in Photosynthesis and Respiration. Pp. 321-362. Springer, Dordrecht 2004.

Tsimilli-Michael M.: Revisiting JIP-test: An educative review on concepts, assumptions, approximations, definitions and terminology. - Photosynthetica 58: 275-292, 2020.

Wang X.-G., Zhao X.-H., Jiang C.-J. et al.: Effects of potassium deficiency on photosynthesis and photo-protection mechanisms in soybean (Glycine max (L.) Merr.). - J. Integr. Agr. 14: 856-863, 2015.

Yusuf M.A., Kumar D., Rajwanshi R. et al.: Overexpression of $\gamma$-tocopherol methyl transferase gene in transgenic Brassica juncea plants alleviates abiotic stress: physiological and chlorophyll $a$ fluorescence measurements. - BBABioenergetics 1797: 1428-1438, 2010.

Zhao D., Oosterhuis D.M, Bednarz C.W.: Influence of potassium deficiency on photosynthesis, chlorophyll content, and chloroplast ultrastructure of cotton plants. - Photosynthetica 39: 103-109, 2001.

Zhao X., Du K., Zhao Y. et al.: Effects of different potassium stress on leaf photosynthesis and chlorophyll fluorescence in maize (Zea mays L.) at seedling stage. - Agr. Sci. 7: 44-53, 2016.

Živčák M., Olšovská, K., Slamka P. et al.: Measurements of chlorophyll fluorescence in different leaf positions may detect nitrogen deficiency in wheat. - Zemdirbyste 101: 437-444, 2014. 
Appendix. Definitions and equations of JIP-test parameters according to Strasser et al. (2004), Ref. [1]; Yusuf et al. (2010), Ref. [2]; and Stirbet and Govindjee (2011), Ref. [3].

\begin{tabular}{|c|c|c|c|c|}
\hline Parameter & Other name(s) & Formula & Description & Ref. \\
\hline $\mathrm{F}_{\mathrm{o}}$ & $\mathrm{F}_{0}, \mathrm{~F}_{\text {open }}$ & $\mathrm{F}_{0.05 \mathrm{~ms}}$ & $\begin{array}{l}\text { First fluorescence value measured after the onset of } \\
\text { actinic illumination and used as initial value for further } \\
\text { calculations }\end{array}$ & [1], [3] \\
\hline $\mathrm{F}_{\mathrm{k}}$ & & $\mathrm{F}_{0.3 \mathrm{~ms}}$ & Fluorescence value at $\mathrm{t}=0.3 \mathrm{~ms}$ & {$[2]$} \\
\hline$F_{j}$ & & $\mathrm{~F}_{2 \mathrm{~ms}}$ & Fluorescence value at $\mathrm{t}=2 \mathrm{~ms}$ & {$[1]$} \\
\hline $\mathrm{F}_{\mathrm{i}}$ & & $\mathrm{F}_{30 \mathrm{~ms}}$ & Fluorescence value at $\mathrm{t}=30 \mathrm{~ms}$ & {$[1]$} \\
\hline $\mathrm{F}_{\mathrm{m}}$ & $\mathrm{F}_{\mathrm{p}}, \mathrm{F}_{\max }$ & $\mathrm{F}_{\approx 300 \mathrm{~ms}}$ & $\begin{array}{l}\text { Maximal fluorescence value recorded under saturating } \\
\text { illumination; the peak of OJIP curve }\end{array}$ & [1], [3] \\
\hline $\mathrm{T}_{\mathrm{FM}}$ & $t_{\mathrm{Fmax}}, \mathrm{t}$ for $\mathrm{F}_{\mathrm{m}}$ & & Time (in $\mathrm{ms}$ ) to reach maximal fluorescence $\mathrm{F}_{\mathrm{m}}$ & {$[1]$} \\
\hline $\mathrm{A}_{\mathrm{m}}$ & Area & & Area between OJIP curve and line $\mathrm{F}=\mathrm{F}_{\mathrm{m}}$ & {$[1]$} \\
\hline $\mathrm{F}_{\mathrm{v}}$ & & $F_{v}=F_{m}-F_{o}$ & Maximal variable fluorescence & {$[1]$} \\
\hline $\mathrm{V}_{\mathrm{j}}$ & & $\mathrm{V}_{\mathrm{j}}=\left(\mathrm{F}_{\mathrm{j}}-\mathrm{F}_{\mathrm{o}}\right) /\left(\mathrm{F}_{\mathrm{m}}-\mathrm{F}_{\mathrm{o}}\right)$ & Relative variable fluorescence at $\mathrm{t}=2 \mathrm{~ms}$ & {$[1]$} \\
\hline $\mathrm{V}_{\mathrm{i}}$ & & $\mathrm{V}_{\mathrm{i}}=\left(\mathrm{F}_{\mathrm{i}}-\mathrm{F}_{\mathrm{o}}\right) /\left(\mathrm{F}_{\mathrm{m}}-\mathrm{F}_{\mathrm{o}}\right)$ & Relative variable fluorescence at $\mathrm{t}=30 \mathrm{~ms}$ & {$[1]$} \\
\hline $\mathrm{M}_{0}$ & & $\mathrm{M}_{0}=4\left(\mathrm{~F}_{\mathrm{k}}-\mathrm{F}_{\mathrm{o}}\right) /\left(\mathrm{F}_{\mathrm{m}}-\mathrm{F}_{\mathrm{o}}\right)$ & $\begin{array}{l}\text { Approximate initial slope of the fluorescence transient } \\
\text { normalized on the maximal variable fluorescence } F_{v}\end{array}$ & [1], [2] \\
\hline $\mathrm{S}_{\mathrm{m}}$ & & $\mathrm{S}_{\mathrm{m}}=\mathrm{A}_{\mathrm{m}} /\left(\mathrm{F}_{\mathrm{m}}-\mathrm{F}_{\mathrm{o}}\right)$ & Normalized area to $F_{m}$ & {$[1]$} \\
\hline $\mathrm{N}$ & & $\mathrm{N}=\mathrm{S}_{\mathrm{m}} \times \mathrm{M}_{0} \times\left(1 / \mathrm{V}_{\mathrm{j}}\right)$ & $\begin{array}{l}\text { Turnover number; number of } Q_{A} \text { reduction events between } \\
\text { time } 0 \text { and } T_{F M}\end{array}$ & {$[1]$} \\
\hline$\phi_{\mathrm{Po}}$ & $\mathrm{F}_{\mathrm{v}} / \mathrm{F}_{\mathrm{m}}, \mathrm{TR}_{0} / \mathrm{ABS}$ & $\phi_{\mathrm{Po}_{\mathrm{o}}}=\mathrm{F}_{\mathrm{v}} / \mathrm{F}_{\mathrm{m}}=1-\left(\mathrm{F}_{\mathrm{o}} / \mathrm{F}_{\mathrm{m}}\right)$ & Maximum quantum yield of primary PSII photochemistry & [1], [3] \\
\hline$\phi_{\text {Eo }}$ & $\mathrm{ET}_{0} / \mathrm{ABS}, \phi \mathrm{ET}_{0}$ & $\phi_{\mathrm{Eo}}=1-\mathrm{F}_{\mathrm{j}} / \mathrm{F}_{\mathrm{m}}=\phi_{\mathrm{Po}}\left(1-\mathrm{V}_{\mathrm{j}}\right)$ & Quantum yield of electron transport & [1], [3] \\
\hline$\phi_{\mathrm{Ro}}$ & $\mathrm{RE}_{0} / \mathrm{ABS}$ & $\begin{array}{l}\phi_{\mathrm{Ro}}=1-\mathrm{F}_{\mathrm{i}} / \mathrm{F}_{\mathrm{m}}= \\
=\phi_{\mathrm{Po}} \times\left(1-\mathrm{V}_{\mathrm{i}}\right)\end{array}$ & $\begin{array}{l}\text { Quantum yield of electron transport flux until PSI electron } \\
\text { acceptors }\end{array}$ & [1], [3] \\
\hline$\psi_{\text {Eo }}$ & $\mathrm{ET}_{0} / \mathrm{TR}_{0}, \psi \mathrm{ET}_{0}$ & $\psi_{\mathrm{Eo}}=1-V_{\mathrm{j}}$ & $\begin{array}{l}\text { Efficiency/probability with which an electron trapped in } \\
\text { PSII RC is transferred beyond } \mathrm{Q}_{\mathrm{A}^{-}}\end{array}$ & {$[1]$} \\
\hline$\delta_{\mathrm{Ro}}$ & $\mathrm{RE}_{0} / \mathrm{ET}_{0}, \delta \mathrm{RE}_{0}$ & $\delta_{\mathrm{Ro}_{0}}=\left(1-\mathrm{V}_{\mathrm{i}}\right) /\left(1-\mathrm{V}_{\mathrm{j}}\right)$ & $\begin{array}{l}\text { Efficiency/probability with which an electron from } Q_{B} \text { is } \\
\text { transferred until PSI acceptors }\end{array}$ & {$[3]$} \\
\hline $\mathrm{RC} / \mathrm{ABS}$ & $\gamma \mathrm{RC} /(1-\gamma \mathrm{RC})$ & $\mathrm{RC} / \mathrm{ABS}=\phi_{\mathrm{Po}} \times \mathrm{V}_{\mathrm{j}} / \mathrm{M}_{0}$ & Number of $\mathrm{Q}_{\mathrm{A}}$ reducing RCs per PSII antenna chlorophyll & [2], [3] \\
\hline $\mathrm{TR}_{0} / \mathrm{RC}$ & & $\mathrm{TR}_{0} / \mathrm{RC}=\mathrm{M}_{0} \times\left(1 / \mathrm{V}_{\mathrm{j}}\right)$ & Trapped energy flux per $\mathrm{RC}$ at $\mathrm{t}=0$ & {$[1]$} \\
\hline $\mathrm{ET}_{0} / \mathrm{RC}$ & & $\mathrm{ET}_{0} / \mathrm{RC}=\mathrm{M}_{0} \times\left(1 / \mathrm{V}_{\mathrm{j}}\right) \times \psi_{\mathrm{Eo}}$ & Electron transport flux further than $\mathrm{Q}_{\mathrm{A}^{-}}$per $\mathrm{RC}$ & [1], [3] \\
\hline $\mathrm{RE}_{0} / \mathrm{RC}$ & & $\mathrm{RE}_{0} / \mathrm{RC}=\left(\mathrm{M}_{0} / \mathrm{V}_{\mathrm{j}}\right) \times\left(1-\mathrm{V}_{\mathrm{i}}\right)$ & Electron transport flux until PSI acceptors per PSII RC & {$[3]$} \\
\hline $\mathrm{PI}_{\mathrm{abs}}$ & & $\begin{array}{l}\mathrm{PI}_{\mathrm{abs}}=(\mathrm{RC} / \mathrm{ABS}) \times \\
\times\left(\phi_{\mathrm{Po}_{0}} / 1-\phi_{\mathrm{Po}_{\mathrm{o}}}\right) \times\left(\psi_{\mathrm{Eo}} / 1-\psi_{\mathrm{Eo}}\right)\end{array}$ & $\begin{array}{l}\text { Performance index (potential) for energy conservation } \\
\text { from photons absorbed by PSII antenna to the reduction } \\
\text { of } \mathrm{Q}_{\mathrm{B}}\end{array}$ & $\begin{array}{l}{[1],[2],} \\
{[3]}\end{array}$ \\
\hline $\mathrm{PI}_{\text {tot }}$ & PI total & $\mathrm{PI}_{\mathrm{tot}}=\mathrm{PI}_{\mathrm{abs}} \times \phi_{\mathrm{Ro}} /\left(1-\phi_{\mathrm{Ro}}\right)$ & $\begin{array}{l}\text { Performance index (potential) for energy conservation } \\
\text { from photons absorbed by PSII antenna until the reduction } \\
\text { of PSI acceptors }\end{array}$ & [2], [3] \\
\hline $\mathrm{ABS} / \mathrm{CS}_{0}$ & & $\approx \mathrm{F}_{\mathrm{o}}$ & Absorption flux per CS, approximated by $\mathrm{F}_{\mathrm{o}}$ & {$[1]$} \\
\hline $\mathrm{RC} / \mathrm{CS}_{0}$ & & $\begin{array}{l}\mathrm{RC} / \mathrm{CS}_{0}=\phi_{\mathrm{Po}_{0}} \times\left(\mathrm{V}_{\mathrm{j}} / \mathrm{M}_{0}\right) \times \\
\times\left(\mathrm{ABS} / \mathrm{CS}_{0}\right)\end{array}$ & Density of active PSII RCs per cross-section (CS) & [1], [3] \\
\hline
\end{tabular}

(C) The authors. This is an open access article distributed under the terms of the Creative Commons BY-NC-ND Licence. 